NOTAS

\title{
REFLEXIONES SOBRE LA TRADUCCIÓN Y SUS TRAICIONES
}

Nora Pasternac*

Hacia 1916 resolvi entregarme al estudio de las literaturas orientales. Al recorrer con entusiasmo y credulidad la versión inglesa de cierto filósofo chino, di con este memorable pasaje: "A un condenado a muente no le importa bordear un precipicio, porque ha renunciado a la vida." En ese punto el traductor colocó un asterisco y me advirtió que su interpretación era preferible a la de otro sinólogo rival que traducía de esta manera: "Los sirvientes destruyen las obras de arte para no tener que juzgar sus bellezas y sus defectos." Entonces, como Paolo y Francesca, dejé de leer. Un misterioso escepticismo se había deslizado en mi alma.

Jorge Luis Borges

$\mathbf{L}$

os traductores tienen (tenemos) siempre anécdotas como ésta que transmite Borges. Constantemente nos hemos topado con los improvisados. "Esos que tanto daño hacen a nuestro idioma porque en doblajes, procesos de subtitulación y artículos de revistas parten de un anémico manejo de la lengua extranjera, un lamentable desconocimiento del español y una falta de cultura cuya amplitud es inabarcable", como dice

* Centro de Lenguas, ITAM.
Federico Patán ${ }^{1}$ al hacer la reseña del Vo Encuentro Internacional de Traductores Literarios, que se llevó a cabo en México en mayo de 1994.

Las observaciones de Federico Patán hacen revivir las agotadoras discusiones que un traductor puede llegar a tener con esos impostores que pululan en el mundo y que pretenden incorporarse al gremio. Para el traductor consciente, lo que escribo aquí

1 “Y usted, ¿̇también traduce?", Sábado, suplemento cultural de uno más uno, 4 de junio de 1994, No 870, p. 10. 
NOTAS

serán trivialidades y lugares comunnes, pero estamos rodeados de tantos trujamanes ineptos presentados pomposamente como traductores que no puedo evitar el recuento de los desastres.

Ignorancia afligente de la lengua extranjera y de la cultura que la lengua vehiculiza, ignorancia imperdonable de la lengua materna. Pero, sobre todo, algo que deberíamos llamar como una especie de enfermedad: el síndrome de la "inhibición de lectura", que se combina con la "patología" de la literalidad. El primero - la imposibilidad de leer propiamente lo traducido - se refleja en la siguiente perla que me tocó afontar: ante la frase "Tu fus cruellement frappée et le vis brusquement disparaître" (Fuiste con crueldad golpeada y lo viste desaparecer bruscamente), la increíble versión daba, contra todas las evidencias que señalaban el absurdo: "Tú fuiste cruelmente golpeada y el tornillo bruscamente desaparecer"; error basado en que el "traductor" no sabía de la existencia del pasado indefinido, "vis"(viste), del verbo "voir"(ver), y en el diccionario se encontró con el sustantivo "vis"(torni1lo), (femenino en francés, pero dejemos ese pequeño detalle de lado) y lo colocó en el lugar de su homófono sin plantearse ninguna pregunta por el sentido total de lo que él mismo leía y daba a leer.

En lo que se refiere a la literalidad, permítaseme transmitir una genialidad de otro aficionado que vierte la frase latina "sepulcrum albeatum" li- teralmente como "sepulcro blanqueado", cuando en realidad se trata de una expresión que en la cultura latina quiere decir "hermosura engañosa"; es decir, de una metáfora que debemos interpretar, decodificar y eventualmente saber perder como literalidad para recuperar en beneficio de un sentido coherente. $O$ al contrario, saber encontrar equivalentes simples para una expresión que, traducida literalmente no significa nada en español; como esta perla pequeña y que puede pasar inadvertida: traducir "hágase la pena" (donnez-vous la peine) literalmente en lugar de su equivalente "tómese el trabajo", expresión en la que ningún término corresponde exactamente al original, pero que no puede ser traducida de otra manera.

A veces, para compensar las carencias, algunos suelen recurrir a expedientes casi intimidatorios, como un anuncio de la publicación de la versión al español de un texto de psicoanálisis en el que se proclamaba: "reescritura de X", por "traducción de X". No conozco la dicha "reescritura", y no puedo prejuzgar sobre su cálidad, pero parece mera presunción no llamar a las cosas por su nombre. En primer lugar, porque toda buena traducción es obligatoriamente una nueva escritura del texto. En segundo, porque pertenecer a la confraternidad de los traductores es un honor. Se comparte, en modesta medida, la condición que el Cortázar políglota ha adoptado tantas veces, o la de Borges, tan consuetudinariamente traductor, o la de 
Octavio Paz o la de Alfonso Reyes... Me detengo aquí, pues la lista es interminable y, ya se sabe, cada traductor tiene su repertorio personal de "grandes" con el que no sólo se consuela del destino de pobreza y del ninguneo que frecuentemente le toca en suerte (falta de mención de su nombre en las resenas, ausencia de reconocimiento, olvido de su opinión cuando debiera ser consultado a la hora de las modificaciones, revisiones y correcciones), sintiendo como "despintan" sobre él los méritos de tan eminentes colegas; sino, sobre todo, porque muchas veces con esos escritores ha aprendido tanto como de su experiencia propia y frecuentemente más que en los cursos que pudo haber seguido institucionalmente.

Una mención aparte merecen las notas aclaratorias del traductor. Casi nadie ha prestado atención a este fenómeno, aunque suele considerarse que las notas al pie de página son el fracaso, la vergüenza del traductor. Tal vez la afirmación parezca extrema, porque es obvio que hay ocasiones en las que se debe renunciar a la transmisión de un elemento fónico o de un juego de palabras para no deformar justamente la intención del autor. Tampoco me refiero a las notas indispensables sobre datos de civilización y cultura que püeden ser extremadamente enigmáticos para el lector. Pero si consideramos que la lógica del paso de un texto de una lengua a otra consiste en colocar al lector (en este caso hispano-hablante) en la misma (mutatis mutandis) posición que la del que se enfrenta con el texto en el idioma original, sin que sea necesario en lo posible, explicarse con una nota al pie de página, las notas del traductor son un asunto delicado y deben reducirse a un mínimo indispensable. En todo caso, antes de rendirse ante la intraductibilidad, hay que hacer un largo y profundo trabajo para resolver el problema, desplazando si es necesario las piezas con que se va a ordenar el nuevo texto en la lengua meta. Verbigracia, si en la lengua de origen se presenta un arcaísmo en algún punto y no puede ser exactamente vertido en el mismo lugar, se puede recrear en otro punto de la oración y con otras formas. Lo mismo ocurrirá con cualquier otro fenómeno de lengua: puntuación, homofonías, juegos, rimas internas, niveles de habla, modismos, idiotismos, etc.; en suma, cualquier manifestación típica de una lengua que no tenga un equivalente exacto en la otra.

Puedo dar un ejemplo bastante simple de mi propia experiencia. Me encuentro con el siguiente texto en francés, de un psicoanalista que describe distintas manifestaciones de paranoia interpretativa (en cierto modo, de traducción) por parte de algunos pacientes, quienes, a su vez, consideran cada elemento del discurso que los demás les dirigen como signos interpretables generalmente de manera persecutoria:

"Nous désirons ta guérison.", écrit un frère à une interprétatrice. Lisant cela, elle remarque que le point qui clôt la phrase est ici anor- 
NOTAS

malement gros; elle lit donc: "Nous ne désirons point ta guérison."(Subrayo el problema.)

Se trata de un juego basado en la existencia de una doble negación en francés "ne...point", que debe traducirse por una negación simple en español. Pero como el segundo término francés también quiere decir "punto", si lo tomamos como palabra aislada, puede ser objeto de un juego, algo así como "no-punto". Por eso la enferma "lee" en la presencia de un punto "anormalmente grande" al final de la frase afirmativa una escondida alusión a la negación. Como eso es imposible de transmitir tal cual en español, yo preferí hacer algunas transformaciones que no modificaban esencialmente el sentido y en cambio evitaban la pesada explicación o la eventual nota del traductor y suprimí el punto:

"Deseamos tu curación", escribe un hermano a una interpretadora. Al leer esto, ella nota que no hay un punto que cierre la frase, que no hay nada. Entonces lee: "No deseamos nada tu curación".

El truco permite recuperar la doble negación que efectivamente existe en español en la mayoría de los casos, aunque no siempre coincida con la doble negación del francés.

Volviendo a la nefasta proliferación de notas al pie, obra del traductor abusivo, veamos también algunos casos. Aquí es interesante constatar que cuando el trabajo es verdaderamente malo el desatre se percibe sin necesidad de conocer el texto en su lengua original, sólo con la versión en español. Por ejemplo, en un Tratado de Ciencia Política tomos I y II, de Georges Bourdeau, publicados por la Unam en 1984, se enumeran: "el nacionalismo, el populismo, el comunismo, el socialismo, el fascismo, y otros 'istmos" (sic). Supongamos que se trata de una errata que todo traductor debe saber corregir. En este caso no sólo no se corrige por el obvio "ismos", sino que el traductor se ve en la obligación de poner un asterisco para aclarar que un "istmo" es un "brazo de tierra etc.,etc.". Dicho sea de paso, estos tomos del Tratado de ciencia política llegan a ser casi ofensivos por la falta de criterio en el uso de las notas aclaratorias del traductor: se nos explican términos como "ad hoc", "ilogismo", "bárbaro", "Sub specie alternitatis" (sic) y una cantidad tan grande de palabras más, que la lectura se vuelve sumamente fastidiosa. Sin mencionar el hecho tan conocido de que si el lector no es el que hace la búsqueda de los términos que no comprende, nunca los incorporará ni fijará. Con lo cual, la supuesta intención pedagógica de tantas explicaciones se pierde totalmente.

El otro ejemplo no es mucho más sutil, pero demuestra el mismo aturdimiento y una ausencia total de criterio sobre la utilidad de las notas del traductor. Se encuentra en la revista $\mathrm{Sa}$ ber ver. Lo contemporáneo en el arte, marzo-abril de 1994, № 15, dedicado a "Moreau y los escultores mayas". 
Se presenta de la siguiente manera, recargado de aclaraciones al pie de página; lo transcribo tal cual, con los números de notas que el texto tiene, aunque me detendré sólo en una:

El arte del siglo XIX ve desarrollarse, paralelamente, tendencias muy distintas entre sí: el romanticismo de Delacroix(20), el academicismo(21) de Ingres(22), el realismo programado y exagerado de Courbet(23) y el impresionismo temprano de Manet(24), que tuvo importantes repercusiones en la obra de los artistas impresionistas(25) y postimpresionistas(26).

En este pequeño párrafo vemos la presencia de siete (!) notas aclaratorias, y de esta manera aparece redactado todo el fascículo. Analicemos la nota prometida. Es la número 23 y dice así:

Gustave Courbet (1819-1877), pintor francés que escogió representar temas de la vida cotidiana, escenas de campo, marinas, paisajes y naturalezas muertas con una visión sincera yobjetiva. (En las dos citas, yo subrayo.)

O sea: el texto dice una cosa y la nota lo contradice ...o al revés si se prefiere. La gran mayoría de las notas al pie que acompañan al cuerpo del texto en esta publicación son inútiles y presuponen una idea de la difusión de la "alta cultura" parcelada y fraccionada en dosis homeopáticas. Y a pesar del fragmentarismo, siguiendo con las metáforas médicas, se puede decir paradójicamente que tanta abundancia de datos predigeridos debe producir una intoxicación informativa mayúscula en cualquier lector.

En un texto que está dirigido a personas cultas, el servicial "traductor" (por cierto, su impericia se percibe en la monótona traducción de todos los pronombres sujeto de los verbos, que no son necesarios en español y por la imposibillidad de comprender que las oraciones intercaladas en francés no pueden serlo siempre en español) reemplaza a los lectores poniendo una nota al pie que oscurece completamente lo que en el artículo ya estaba perfectamente claro:

Los griegos practicaban, bajo el nombre de epiclère, (NdT:Epikleros, nombre genérico del heredero, del que se desprenden diferentes especies.) un tipo de transmisión muy excepcional aunque regulada. En ausencia de un heredero legítimo (de un hijo varón) un griego podía remitir su patrimonio a un nieto por la vía de una de sus hijas, quien, antes de irse a fundar un hogar distinto del de su padre, se consagraba a esta transmisión. Guardiana, junto con su marido, del hogar de su padre, ambos debían mantener congelado el patrimonio hasta que pudiera ser remitido a quien correspondiera.

A pesar de la torpeza de la redacción en español, se comprende clara- 


\section{NOTAS}

mente en qué consiste el fenómeno. Por lo tanto, toda aclaración es impertinente y sólo el provincialismo y la ineptitud pueden hacernos creer que se requiere una nota para el término en cuestión.

Me detengo aquí, pues el fastidio es interminable, como la lista de tonterías cometidas.

Para concluir, debería ofrecer algunas consideraciones teóricas, aunque me gustaría conservar el tono ligero y algo informal que he mantenido hasta aquí.

Obviamente, quien traduce un texto da a leer en otra lengua lo antes escrito. Traducir no es sólo traducir palabras, sino toda una cultura vehiculizada por esas palabras. Además, ante un texto accesible en la misma lengua en que fue escrito, la lectura abre la posibilidad, para el lector, de la ineludible intervención de su subjetividad, que funciona como una rejilla organizadora, capaz de producir efectos de sentido variados. En cambio, en la traducción de un escrito en otra lengua, el traductor habrá de proponerse ofrecer a un presunto lector un texto que lo sitúe en la posibilidad de afrontar las "mismas" alternativas de sentido que el que lee el texto en la lengua original. Entrecomillo porque tal "mismidad" es un ideal, en última instancia inalcanzable, pero que orienta, pese a todo, el esfuerzo de la traducción. Pues todo traductor sabe que no hay traducción sin "resto", sin algo intraducible; que, como dice Roman Jakobson, "las lenguas difieren por lo que deben expresar y no por lo que pueden expresar". Curiosa paradoja: una lengua se define por lo que me impide decir y no por lo que me permite decir. Por lo tanto, la traducción debe tener en cuenta la articulación de lo literal - la elección del "un-sentido" - sin invalidar la prevalencia del imaginario del sentido en la traducción: por lo contrario, esa articulación es la que puede permitir que el lector en otra lengua participe de la perplejidad, de la dificultad que experimenta el lector del original. La traducción tendrá en cuenta aquello que participa de lo literal, pero sin confundirse con lo literal. Porque descifrar no es traducir, así como traducir no es descifrar. El sentido no debe transmitirse término a término, sino en la elaboración de una frase, un párrafo, un período o una proposición en la lengua meta.

Por otra parte, el buen traductor sabe que renuncia a cierta libertad al someterse al dique que le impone el texto de otro. La tarea del traductor sacrifica algo de la dimensión del sujeto a una vocación de la transmisión de un texto. Debe traducir el contenido de éste y también su sentido; para lo cual, como hemos visto, entra en un juego entre lo mismo y lo diferente subordinado a lo mismo. La falla constitutiva de la traducción - o sea la imposibilidad de traducirlo todo-, su resto inevitable, exige la articulación con ella de la transcripción (la regulación de la traducción sobre el sonido fundamentalmente) y con la transliteración (la regulación de la traducción a partir del problema que plantean dos 
NOTAS

escrituras diferentes en su principio mismo, es decir, en su letra) para poder reproducir la estructura de la relación de otro lector, en otra lengua, con ese texto. 